\title{
Some fixed point theorems for generalized contractive mappings in complete metric spaces
}

\author{
Nawab Hussain ${ }^{1}$, Vahid Parvaneh², Bessem Samet ${ }^{3 *}$ and Calogero Vetro ${ }^{4}$
}

${ }^{\text {"Correspondence: }}$

bsamet@ksu.edu.sa

${ }^{3}$ Department of Mathematics,

College of Science, King Saud

University, P.O. Box 2455, Riyadh,

11451, Saudi Arabia

Full list of author information is

available at the end of the article

\begin{abstract}
We introduce new concepts of generalized contractive and generalized $\alpha$-Suzuki type contractive mappings. Then, we obtain sufficient conditions for the existence of a fixed point of these classes of mappings on complete metric spaces and $b$-complete b-metric spaces. Our results extend the theorems of Ćirić, Chatterjea, Kannan and Reich.
\end{abstract}

MSC: Primary $47 \mathrm{H} 10$; secondary $54 \mathrm{H} 25$

Keywords: complete metric space; fixed point; weak C-contraction

\section{Introduction and preliminaries}

The theoretical framework of fixed point theory has been an active research field over the last three decades. Of course, the Banach contraction mapping principle [1] is the first important result on fixed points for contractive-type mappings. This well-known theorem, which is an essential tool in many branches of mathematical analysis, first appeared in an explicit form in Banach's thesis in 1922, where it was used to establish the existence of a solution for an integral equation. So far, according to its importance and simplicity, several authors have obtained many interesting extensions and generalizations of the Banach contraction principle (see [2-10] and the references therein). Some of such generalizations are obtained by contraction conditions described by rational expressions (see [11-13]).

Throughout this paper, $X$ is assumed to be a nonempty set. Then, the concepts of $T$-contraction and $C$-contraction have been introduced, respectively, by Kannan [14] and Chatterjea [15] as follows.

Definition 1.1 Let $(X, d)$ be a metric space. A mapping $f: X \rightarrow X$ is said to be:

(i) a $C$-contraction (see [15]) if there exists $\alpha \in\left(0, \frac{1}{2}\right)$ such that for all $x, y \in X$ the following inequality holds:

$$
d(f x, f y) \leq \alpha[d(x, f y)+d(y, f x)]
$$

(ii) a $K$-contraction (see [14]) if there exists $\alpha \in\left(0, \frac{1}{2}\right)$ such that for all $x, y \in X$ the following inequality holds:

$$
d(f x, f y) \leq \alpha[d(x, f x)+d(y, f y)]
$$

(c) 2015 Hussain et al. This article is distributed under the terms of the Creative Commons Attribution 4.0 International License (http://creativecommons.org/licenses/by/4.0/), which permits unrestricted use, distribution, and reproduction in any medium, provided you give appropriate credit to the original author(s) and the source, provide a link to the Creative Commons license, and indicate if changes were made. 
(iii) a Reich contraction (see [9]) iff for all $x, y \in X$ there exist nonnegative numbers $q, r$, $s$ such that $q+r+s<1$ and

$$
d(f x, f y) \leq q d(x, y)+r d(x, f x)+s d(y, f y)
$$

(iv) a Ćirić contraction (see [3]) iff for all $x, y \in X$ there exist nonnegative numbers $q, r$, $s$ and $t$ such that $q+r+s+2 t<1$ and

$$
d(f x, f y) \leq q d(x, y)+r d(x, f x)+s d(y, f y)+t[d(x, f y)+d(y, f x)] .
$$

In 1968 Kannan (see [14]) established a fixed point theorem for a $K$-contraction. Also, in 1972 Chatterjea (see [15]) proved that if $(X, d)$ is a complete metric space, then every $C$-contraction on $X$ has a unique fixed point.

Let $\mathfrak{S}$ denote the class of all real functions $\beta:[0, \infty) \rightarrow[0,1)$ satisfying the condition

$$
\beta\left(t_{n}\right) \rightarrow 1 \text { implies that } t_{n} \rightarrow 0 \quad \text { as } n \rightarrow \infty .
$$

One of the interesting results which generalizes the Banach contraction principle was given by Samet et al. [16] by defining $\alpha-\psi$-contractive mappings.

Definition 1.2 (see [16]) Let $f: X \rightarrow X$ be a mapping, and let $\alpha: X \times X \rightarrow[0, \infty)$ be a function. We say that $f$ is an $\alpha$-admissible mapping if

$$
x, y \in X, \quad \alpha(x, y) \geq 1 \quad \Longrightarrow \quad \alpha(f x, f y) \geq 1 .
$$

Denote by $\Psi^{\prime}$ the family of all nondecreasing functions $\psi:[0, \infty) \rightarrow[0, \infty)$ such that $\sum_{n=1}^{\infty} \psi^{n}(t)<\infty$ for all $t>0$, where $\psi^{n}$ is the $n$th iterate of $\psi$.

Theorem 1.3 (see [16]) Let $(X, d)$ be a complete metric space, and let $f$ be an $\alpha$-admissible mapping. Assume that

$$
\alpha(x, y) d(f x, f y) \leq \psi(d(x, y))
$$

where $\psi \in \Psi^{\prime}$. Also, suppose that the following assertions hold:

(i) there exists $x_{0} \in X$ such that $\alpha\left(x_{0}, f x_{0}\right) \geq 1$;

(ii) either $f$ is continuous, or, for any sequence $\left\{x_{n}\right\}$ in $X$ with $\alpha\left(x_{n}, x_{n+1}\right) \geq 1$ for all $n \in \mathbb{N} \cup\{0\}$ such that $x_{n} \rightarrow x$ as $n \rightarrow \infty$, we have $\alpha\left(x_{n}, x\right) \geq 1$ for all $n \in \mathbb{N} \cup\{0\}$.

Then $f$ has a fixed point.

Definition 1.4 (see [17]) Let $f: X \rightarrow X$ and $\alpha: X \times X \rightarrow[0,+\infty)$. We say that $f$ is a triangular $\alpha$-admissible mapping if

(T1) $\alpha(x, y) \geq 1$ implies $\alpha(f x, f y) \geq 1, x, y \in X$;

(T2) $\left\{\begin{array}{l}\alpha(x, z) \geq 1, \\ \alpha(z, y) \geq 1\end{array}\right.$ implies $\alpha(x, y) \geq 1, x, y, z \in X$.

Lemma 1.5 (see [17]) Let $f$ be a triangular $\alpha$-admissible mapping. Assume that there exists $x_{0} \in X$ such that $\alpha\left(x_{0}, f x_{0}\right) \geq 1$. Define a sequence $\left\{x_{n}\right\}$ by $x_{n}=f^{n} x_{0}$. Then

$$
\alpha\left(x_{m}, x_{n}\right) \geq 1 \text { for all } m, n \in \mathbb{N} \text { with } m<n
$$


In this paper, we introduce new concepts of generalized contractive and generalized $\alpha$-Suzuki type contractive mappings. Then, we obtain sufficient conditions for the existence of a fixed point of these classes of mappings on complete metric spaces and $b$-complete $b$-metric spaces. In particular, our results extend the theorems of Ćirić, Chatterjea, Kannan and Reich.

\section{Generalization of Ćirić, Chatterjea, Kannan and Reich contractions}

In [18], Jleli and Samet introduced a new type of contractive mappings and established a new fixed point theorem for such mappings in the setting of generalized metric spaces.

Consistent with [18], we denote by $\Psi$ the set of all functions $\psi:[0, \infty) \rightarrow[1, \infty)$ satisfying the following conditions:

$\left(\psi_{1}\right) \psi$ is nondecreasing and $\psi(t)=1$ if and only if $t=0$;

$\left(\psi_{2}\right)$ for each sequence $\left\{t_{n}\right\} \subseteq(0, \infty), \lim _{n \rightarrow \infty} \psi\left(t_{n}\right)=1$ if and only if $\lim _{n \rightarrow \infty} t_{n}=0$;

$\left(\psi_{3}\right)$ there exist $r \in(0,1)$ and $\ell \in(0, \infty]$ such that $\lim _{t \rightarrow 0^{+}} \frac{\psi(t)-1}{t^{r}}=\ell$;

$\left(\psi_{4}\right) \psi(a+b) \leq \psi(a) \psi(b)$ for all $a, b>0$.

Theorem 2.1 (see [18], Corollary 2.1) Let $(X, d)$ be a complete metric space and $f: X \rightarrow X$ be a mapping. Suppose that there exist $\psi \in \Psi$ and $k \in(0,1)$ such that

$$
x, y \in X, \quad d(f x, f y) \neq 0 \quad \Longrightarrow \quad \psi(d(f x, f y)) \leq[\psi(d(x, y))]^{k} .
$$

Then $f$ has a unique fixed point.

Observe that the Banach contraction principle follows immediately from the above theorem.

By introducing the following new concept, first we extend the result of Jleli and Samet, then we obtain some new generalizations of the Banach contraction principle.

Definition 2.2 Let $(X, d)$ be a metric space, and let $f: X \rightarrow X$ be a mapping.

$f$ is said to be a JS-contraction whenever there are a function $\psi \in \Psi$ and positive real numbers $k_{1}, k_{2}, k_{3}, k_{4}$ with $0 \leq k_{1}+k_{2}+k_{3}+2 k_{4}<1$ such that

$$
\begin{aligned}
\psi(d(f x, f y)) \leq & {[\psi(d(x, y))]^{k_{1}}[\psi(d(x, f x))]^{k_{2}}[\psi(d(y, f y))]^{k_{3}} } \\
& \times[\psi(d(x, f y)+d(y, f x))]^{k_{4}}
\end{aligned}
$$

for all $x, y \in X$.

Our first result is the following.

Theorem 2.3 Let $(X, d)$ be a complete metric space and $f: X \rightarrow X$ be a continuous JScontraction. Then $f$ has a unique fixed point.

Proof Let $x_{0} \in X$ be arbitrary. For $x_{0} \in X$, we define the sequence $\left\{x_{n}\right\}$ by $x_{n}=f^{n} x_{0}=f x_{n-1}$. Also, if there exists $n_{0} \in \mathbb{N}$ such that $x_{n_{0}}=x_{n_{0}+1}$, then $x_{n_{0}}$ is a fixed point of $f$, and we have nothing to prove. Thus, we assume that $x_{n} \neq x_{n+1}$, i.e., $d\left(f x_{n-1}, f x_{n}\right)>0$ for all $n \in \mathbb{N} \cup\{0\}$. 
Now, we will prove that

$$
\lim _{n \rightarrow \infty} d\left(x_{n}, x_{n+1}\right)=0
$$

Since $f$ is a JS-contraction, then, by using condition (2.1), we obtain that

$$
\begin{aligned}
\psi( & \left.d\left(x_{n+1}, x_{n}\right)\right) \\
= & \psi\left(d\left(f x_{n}, f x_{n-1}\right)\right) \\
\leq & {\left[\psi\left(d\left(x_{n}, x_{n-1}\right)\right)\right]^{k_{1}}\left[\psi\left(d\left(x_{n}, f x_{n}\right)\right)\right]^{k_{2}}\left[\psi\left(d\left(x_{n-1}, f x_{n-1}\right)\right)\right]^{k_{3}} } \\
& \times\left[\psi\left(d\left(x_{n}, f x_{n-1}\right)+d\left(x_{n-1}, f x_{n}\right)\right)\right]^{k_{4}} \\
\leq & {\left[\psi\left(d\left(x_{n}, x_{n-1}\right)\right)\right]^{k_{1}}\left[\psi\left(d\left(x_{n}, x_{n+1}\right)\right)\right]^{k_{2}}\left[\psi\left(d\left(x_{n-1}, x_{n}\right)\right)\right]^{k_{3}}\left[\psi\left(d\left(x_{n-1}, x_{n+1}\right)\right)\right]^{k_{4}} } \\
\leq & {\left[\psi\left(d\left(x_{n}, x_{n-1}\right)\right)\right]^{k_{1}+k_{3}}\left[\psi\left(d\left(x_{n}, x_{n+1}\right)\right)\right]^{k_{2}}\left[\psi\left(d\left(x_{n-1}, x_{n}\right)\right)\right]^{k_{4}}\left[\psi\left(d\left(x_{n}, x_{n+1}\right)\right)\right]^{k_{4}} . }
\end{aligned}
$$

Therefore, we write

$$
1<\psi\left(d\left(x_{n+1}, x_{n}\right)\right) \leq\left[\psi\left(d\left(x_{n}, x_{n-1}\right)\right)\right]^{\frac{k_{1}+k_{3}+k_{4}}{1-k_{2}-k_{4}}} \leq\left[\psi\left(d\left(x_{1}, x_{0}\right)\right)\right]^{\left(\frac{k_{1}+k_{3}+k_{4}}{1-k_{2}-k_{4}}\right)^{n}} .
$$

This gives us that

$$
\lim _{n \rightarrow \infty} d\left(x_{n}, x_{n+1}\right)=0
$$

by our assumptions about the function $\psi$. From similar arguments as in the proof of Theorem 2.1 of [18] it follows that there exists $n_{1} \in \mathbb{N}$ such that

$$
d\left(x_{n}, x_{n+1}\right) \leq \frac{1}{n^{\frac{1}{r}}}
$$

for all $n \geq n_{1}$.

Now, for $m>n>n_{1}$, we have

$$
d\left(x_{n}, x_{m}\right) \leq \sum_{i=n}^{m-1} d\left(x_{i}, x_{i+1}\right) \leq \sum_{i=n}^{m-1} \frac{1}{i^{\frac{1}{r}}}
$$

Since $0<r<1$, then $\sum_{i=n}^{\infty} \frac{1}{i \frac{1}{r}}$ converges and hence $d\left(x_{n}, x_{m}\right) \rightarrow 0$ as $m, n \rightarrow \infty$. Thus, we proved that $\left\{x_{n}\right\}$ is a Cauchy sequence. Completeness of $(X, d)$ ensures that there exists $x^{*} \in X$ such that $x_{n} \rightarrow x^{*}$ as $n \rightarrow \infty$. Next, since $f$ is a continuous mapping, then $x_{n+1}=$ $f x_{n} \rightarrow f x^{*}$ as $n \rightarrow \infty$, i.e., $x^{*}=f x^{*}$. Thus, $f$ has a fixed point.

Finally, suppose that there exists $z \neq x^{*}$ such that $z=f z$. Clearly, $d\left(z, x^{*}\right)=d\left(f z, f x^{*}\right) \neq 0$ and so we can apply condition (2.1) for the pair $\left(z, x^{*}\right)$. Now, by (2.1) we get

$$
1<\psi\left(d\left(z, x^{*}\right)\right)=\psi\left(d\left(f z, f x^{*}\right)\right) \leq\left[\psi\left(d\left(z, x^{*}\right)\right)\right]^{k_{1}+2 k_{4}}<\psi\left(d\left(z, x^{*}\right)\right)
$$

which leads to contradiction. Thus, we have a unique fixed point of $f$ in $X$.

For specific choices of function $\psi$, we obtain some significant results. First, by taking $\psi(t)=e^{\sqrt{t}}$ in (2.1), we state a generalization of Ćirić result in [3]. 
Theorem 2.4 Let $(X, d)$ be a complete metric space and $f: X \rightarrow X$ be a continuous mapping. Suppose that there exist positive real numbers $k_{1}, k_{2}, k_{3}, k_{4}$, with $0 \leq k_{1}+k_{2}+k_{3}+2 k_{4}<$ 1 , such that

$$
\sqrt{d(f x, f y)} \leq k_{1} \sqrt{d(x, y)}+k_{2} \sqrt{d(x, f x)}+k_{3} \sqrt{d(y, f y)}+k_{4} \sqrt{d(x, f y)+d(y, f x)}
$$

for all $x, y \in X$. Then $f$ has a unique fixed point.

Remark 2.5 Notice that condition (2.2) is equivalent to

$$
\begin{aligned}
d(f x, f y) \leq & k_{1}^{2} d(x, y)+{k_{2}}^{2} d(x, f x)+k_{3}^{2} d(y, f y)+k_{4}^{2}[d(x, f y)+d(y, f x)] \\
& +2 k_{1} k_{2} \sqrt{d(x, y) d(x, f x)}+2 k_{1} k_{3} \sqrt{d(x, y) d(y, f y)} \\
& +2 k_{1} k_{4} \sqrt{d(x, y)[d(x, f y)+d(y, f x)]}+2 k_{2} k_{3} \sqrt{d(x, f x) d(y, f y)} \\
& +2 k_{2} k_{4} \sqrt{d(x, f x)[d(x, f y)+d(y, f x)]}+2 k_{3} k_{4} \sqrt{d(y, f y)[d(x, f y)+d(y, f x)]} .
\end{aligned}
$$

Next, in view of Remark 2.5, by taking $k_{1}=k_{4}=0$ in Theorem 2.4, we obtain the following extension of Kannan result.

Theorem 2.6 Let $(X, d)$ be a complete metric space and $f: X \rightarrow X$ be a continuous mapping. Suppose that there exist positive real numbers $k_{2}, k_{3}$, with $0 \leq k_{2}+k_{3}<1$, such that

$$
d(f x, f y) \leq k_{2}^{2} d(x, f x)+k_{3}^{2} d(y, f y)+2 k_{2} k_{3} \sqrt{d(x, f x) d(y, f y)}
$$

for all $x, y \in X$. Then $f$ has a unique fixed point.

On the other hand, by taking $k_{1}=k_{2}=k_{3}=0$ in Theorem 2.4, we obtain the following Chatterjea type result.

Theorem 2.7 Let $(X, d)$ be a complete metric space and $f: X \rightarrow X$ be a continuous mapping. Suppose that there exists $k_{4} \in\left[0, \frac{1}{2}\right)$ such that

$$
d(f x, f y) \leq k_{4}^{2}[d(x, f y)+d(y, f x)]
$$

for all $x, y \in X$. Then $f$ has a unique fixed point.

From Theorem 2.4, by taking $k_{4}=0$, we obtain the extension of Reich contraction.

Theorem 2.8 Let $(X, d)$ be a complete metric space and $f: X \rightarrow X$ be a continuous mapping. Suppose that there exist positive real numbers $k_{1}, k_{2}, k_{3}$, with $0 \leq k_{1}+k_{2}+k_{3}<1$, such that

$$
\begin{aligned}
d(f x, f y) \leq & k_{1}^{2} d(x, y)+k_{2}^{2} d(x, f x)+k_{3}^{2} d(y, f y) \\
& +2 k_{1} k_{2} \sqrt{d(x, y) d(x, f x)}+2 k_{1} k_{3} \sqrt{d(x, y) d(y, f y)}+2 k_{2} k_{3} \sqrt{d(x, f x) d(y, f y)}
\end{aligned}
$$

for all $x, y \in X$. Then $f$ has a unique fixed point.

Finally, by taking $\psi(t)=e^{\sqrt[n]{t}}$ in (2.1), we have the following corollary. 
Corollary 2.9 Let $(X, d)$ be a complete metric space and $f: X \rightarrow X$ be a continuous mapping. Suppose that there exist positive real numbers $k_{1}, k_{2}, k_{3}, k_{4}$, with $0 \leq k_{1}+k_{2}+k_{3}+2 k_{4}<$ 1 , such that

$$
\sqrt[n]{d(f x, f y)} \leq k_{1} \sqrt[n]{d(x, y)}+k_{2} \sqrt[n]{d(x, f x)}+k_{3} \sqrt[n]{d(y, f y)}+k_{4} \sqrt[n]{d(x, f y)+d(y, f x)}
$$

for all $x, y \in X$. Then $f$ has a unique fixed point.

\section{Generalized $\alpha$-Suzuki type contractions}

Czerwik in [19] introduced the concept of $b$-metric space. Since then, several papers discussed fixed point results for single-valued and multi-valued operators in $b$-metric spaces (see, e.g., $[19,20])$.

Definition 3.1 Let $X$ be a (nonempty) set and $s \geq 1$ be a given real number. A function $d: X \times X \rightarrow \mathbb{R}^{+}$is a $b$-metric if, for all $x, y, z \in X$, the following conditions are satisfied:

(b $\left.\mathrm{b}_{1}\right) d(x, y)=0$ iff $x=y$,

$\left(\mathrm{b}_{2}\right) d(x, y)=d(y, x)$,

$\left(\mathrm{b}_{3}\right) d(x, z) \leq s[d(x, y)+d(y, z)]$.

In this case, the pair $(X, d)$ is called a $b$-metric space.

Definition 3.2 (see [21]) Let $(X, d)$ be a $b$-metric space.

(i) A sequence $\left\{x_{n}\right\}$ in $X$ is called $b$-convergent if and only if there exists $x \in X$ such that $d\left(x_{n}, x\right) \rightarrow 0$ as $n \rightarrow \infty$. In this case, we write $\lim _{n \rightarrow \infty} x_{n}=x$.

(ii) A sequence $\left\{x_{n}\right\}$ in $X$ is said to be $b$-Cauchy if and only if $d\left(x_{n}, x_{m}\right) \rightarrow 0$ as $n, m \rightarrow \infty$.

(iii) The $b$-metric space $(X, d)$ is $b$-complete if every $b$-Cauchy sequence in $X$ is $b$-convergent.

Note that a $b$-metric need not be a continuous function. The following example (corrected from [22]) illustrates this fact.

Example 3.3 Let $X=\mathbb{N} \cup\{\infty\}$ and let $d: X \times X \rightarrow \mathbb{R}$ be defined by

$$
d(m, n)= \begin{cases}0 & \text { if } m=n, \\ \left|\frac{1}{m}-\frac{1}{n}\right| & \text { if one of } m, n \text { is even and the other is even or } \infty \\ 5 & \text { if one of } m, n \text { is odd and the other is odd (and } m \neq n) \text { or } \infty \\ 2, & \text { otherwise }\end{cases}
$$

It can be checked that for all $m, n, p \in X$, we have

$$
d(m, p) \leq \frac{5}{2}[d(m, n)+d(n, p)] .
$$

Thus, $(X, d)$ is a $b$-metric space (with $s=5 / 2)$. Let $x_{n}=2 n$ for each $n \in \mathbb{N}$. Then

$$
\begin{gathered}
d(2 n, \infty)=\frac{1}{2 n} \rightarrow 0 \quad \text { as } n \rightarrow \infty, \\
\text { i.e., } x_{n} \rightarrow \infty \text {, but } d\left(x_{n}, 1\right)=2 \nrightarrow 5=d(\infty, 1) \text { as } n \rightarrow \infty .
\end{gathered}
$$


It is easy to prove the following lemma.

Lemma 3.4 Let $(X, d)$ be a b-metric space with $s \geq 1$. If a sequence $\left\{x_{n}\right\} \subseteq X$ is $b$-convergent, then it admits a unique limit.

Now, we consider a new set of real functions, say $\Theta$. Precisely, we modify the set $\Psi$ by substituting the condition $\psi_{3}$ by another condition. Applying this condition we can have a wide range of functions. Thus, we denote by $\Theta$ the set of all functions $\theta:(0, \infty) \rightarrow(1, \infty)$ satisfying the following conditions:

$\left(\theta_{1}\right) \theta$ is nondecreasing;

$\left(\theta_{2}\right)$ for each sequence $\left\{t_{n}\right\} \subseteq(0, \infty), \lim _{n \rightarrow \infty} \theta\left(t_{n}\right)=1$ if and only if $\lim _{n \rightarrow \infty} t_{n}=0$;

$\left(\theta_{3}\right) \theta$ is continuous.

Remark 3.5 It is clear that $f(t)=e^{t}$ does not belong to $\Psi$, but $f(t)=e^{t} \in \Theta$. Another examples are $f(t)=\cosh t$ and $f(t)=1+\ln (1+t)$ for all $t>0$.

In 1962, Edelstein (see [23]) proved an interesting version of the Banach contraction principle. In 2009, Suzuki (see [24]) proved certain remarkable results to improve the results of Banach and Edelstein (see also [22, 25-27]).

Now, we are ready to prove the following Suzuki-Edelstein type theorem. The values of $M(x, y)$ in the sequel appeared recently in [28]. Also, we assume that $\alpha: X \times X \rightarrow$ $(0, \infty)$

Theorem 3.6 Let $(X, d)$ be a b-complete b-metric space with $s>1$, and let $f$ be a triangular $\alpha$-admissible mapping. Suppose that there exist $\theta \in \Theta$ and $k \in(0,1)$ such that

$$
\frac{1}{2 s} d(x, f x) \leq d(x, y) \quad \Longrightarrow \quad \alpha(x, y) \theta\left(s^{2} d(f x, f y)\right) \leq[\theta(M(x, y))]^{k}
$$

for all $x, y \in X$ with $f x \neq f y$, where

$$
\begin{aligned}
M(x, y)= & \max \left\{d(x, y), \frac{d(x, f x) d(x, f y)+d(y, f y) d(y, f x)}{1+s[d(x, f x)+d(y, f y)]},\right. \\
& \left.\frac{d(x, f x) d(x, f y)+d(y, f y) d(y, f x)}{1+d(x, f y)+d(y, f x)}\right\} .
\end{aligned}
$$

Also, suppose that the following assertions hold:

(i) there exists $x_{0} \in X$ such that $\alpha\left(x_{0}, f x_{0}\right) \geq 1$;

(ii) for any sequence $\left\{x_{n}\right\}$ in $X$ with $\alpha\left(x_{n}, x_{n+1}\right) \geq 1$, for all $n \in \mathbb{N} \cup\{0\}$, such that $x_{n} \rightarrow x$ as $n \rightarrow \infty$, we have $\alpha\left(x_{n}, x\right) \geq 1$ for all $n \in \mathbb{N} \cup\{0\}$.

Then $f$ has a fixed point.

Proof Let $x_{0} \in X$ be such that $\alpha\left(x_{0}, f x_{0}\right) \geq 1$. Define a sequence $\left\{x_{n}\right\}$ by $x_{n}=f^{n} x_{0}$ for all $n \in \mathbb{N}$. Since $f$ is an $\alpha$-admissible mapping and $\alpha\left(x_{0}, x_{1}\right)=\alpha\left(x_{0}, f x_{0}\right) \geq 1$, we deduce that $\alpha\left(x_{1}, x_{2}\right)=\alpha\left(f x_{0}, f x_{1}\right) \geq 1$. Continuing this process, we get that $\alpha\left(x_{n}, x_{n+1}\right) \geq 1$ for all $n \in$ $\mathbb{N} \cup\{0\}$. Without loss of generality, we suppose that $x_{n} \neq x_{n+1}$ for all $\mathbb{N} \cup\{0\}$. We will do the proof in the following steps. 
Step I: We will show that $\lim _{n \rightarrow \infty} d\left(x_{n}, x_{n+1}\right)=0$. Since $\alpha\left(x_{n}, x_{n+1}\right) \geq 1$ for each $n \in \mathbb{N}$, and $\frac{1}{2 s} d\left(x_{n-1}, f x_{n-1}\right) \leq d\left(x_{n-1}, x_{n}\right)$ then by (3.1) we have

$$
\begin{aligned}
\theta\left(d\left(x_{n}, x_{n+1}\right)\right) & =\theta\left(d\left(f x_{n-1}, f x_{n}\right)\right) \\
& \leq \alpha\left(x_{n-1}, x_{n}\right) \theta\left(s^{2} d\left(f x_{n-1}, f x_{n}\right)\right) \\
& \leq\left[\theta\left(M\left(x_{n-1}, x_{n}\right)\right)\right]^{k} \\
& =\left[\theta\left(d\left(x_{n-1}, x_{n}\right)\right)\right]^{k} \\
& <\theta\left(d\left(x_{n-1}, x_{n}\right)\right)
\end{aligned}
$$

because

$$
\begin{aligned}
M\left(x_{n-1}, x_{n}\right)= & \max \left\{d\left(x_{n-1}, x_{n}\right), \frac{d\left(x_{n-1}, f x_{n-1}\right) d\left(x_{n-1}, f x_{n}\right)+d\left(x_{n}, f x_{n}\right) d\left(x_{n}, f x_{n-1}\right)}{1+s\left[d\left(x_{n-1}, f x_{n-1}\right)+d\left(x_{n-1}, f x_{n}\right)\right]},\right. \\
& \left.\frac{d\left(x_{n-1}, f x_{n-1}\right) d\left(x_{n-1}, f x_{n}\right)+d\left(x_{n}, f x_{n}\right) d\left(x_{n}, f x_{n-1}\right)}{1+d\left(x_{n-1}, f x_{n}\right)+d\left(x_{n}, f x_{n-1}\right)}\right\} \\
= & \max \left\{d\left(x_{n-1}, x_{n}\right), \frac{d\left(x_{n-1}, x_{n}\right) d\left(x_{n-1}, x_{n+1}\right)+d\left(x_{n}, x_{n+1}\right) d\left(x_{n}, x_{n}\right)}{1+s\left[d\left(x_{n-1}, x_{n}\right)+d\left(x_{n}, x_{n+1}\right)\right]},\right. \\
& \left.\frac{d\left(x_{n-1}, x_{n}\right) d\left(x_{n-1}, x_{n+1}\right)+d\left(x_{n}, x_{n+1}\right) d\left(x_{n}, x_{n}\right)}{1+d\left(x_{n-1}, x_{n+1}\right)+d\left(x_{n}, x_{n}\right)}\right\} \\
= & d\left(x_{n-1}, x_{n}\right) .
\end{aligned}
$$

Therefore, we have

$$
1<\theta\left(d\left(x_{n+1}, x_{n}\right)\right) \leq\left[\theta\left(d\left(x_{n}, x_{n-1}\right)\right)\right]^{k} \leq\left[\theta\left(d\left(x_{1}, x_{0}\right)\right)\right]^{k^{n}} .
$$

This gives us that

$$
\lim _{n \rightarrow \infty} d\left(x_{n}, x_{n+1}\right)=0
$$

by our assumptions about function $\theta$.

Step II: Now, we prove that the sequence $\left\{x_{n}\right\}$ is a $b$-Cauchy sequence. Suppose the contrary, i.e., $\left\{x_{n}\right\}$ is not a $b$-Cauchy sequence. Then there exists $\varepsilon>0$ for which we can find two subsequences $\left\{x_{m_{i}}\right\}$ and $\left\{x_{n_{i}}\right\}$ of $\left\{x_{n}\right\}$ such that $n_{i}$ is the smallest index for which

$$
n_{i}>m_{i}>i \quad \text { and } \quad d\left(x_{m_{i}}, x_{n_{i}}\right) \geq \varepsilon .
$$

This means that

$$
d\left(x_{m_{i}}, x_{n_{i}-1}\right)<\varepsilon .
$$

From (3.3) and using $\left(b_{3}\right)$, we get

$$
\varepsilon \leq d\left(x_{m_{i}}, x_{n_{i}}\right) \leq s d\left(x_{m_{i}}, x_{m_{i}+1}\right)+s d\left(x_{m_{i}+1}, x_{n_{i}}\right) .
$$


Taking the upper limit as $i \rightarrow \infty$, we get

$$
\frac{\varepsilon}{s} \leq \limsup _{i \rightarrow \infty} d\left(x_{m_{i}+1}, x_{n_{i}}\right)
$$

Remember that from (3.2) and $\left(\theta_{1}\right)$ we get

$$
d\left(x_{n}, x_{n+1}\right) \leq d\left(x_{n-1}, x_{n}\right)
$$

for all $n \in \mathbb{N}$. Suppose that there exists $i_{0} \in \mathbb{N}$ such that

$$
\frac{1}{2 s} d\left(x_{m_{i_{0}}}, f x_{m_{i_{0}}}\right)>d\left(x_{m_{i_{0}}}, x_{n_{i_{0}}-1}\right)
$$

and

$$
\frac{1}{2 s} d\left(x_{m_{i_{0}}+1}, f x_{m_{i_{0}}+1}\right)>d\left(x_{m_{i_{0}}+1}, x_{n_{i_{0}}-1}\right) .
$$

Then, from (3.5), we have

$$
\begin{aligned}
d\left(x_{m_{i_{0}}}, x_{m_{i_{0}}+1}\right) & \leq s\left[d\left(x_{m_{i_{0}}}, x_{n_{i_{0}}-1}\right)+d\left(x_{m_{i_{0}}+1}, x_{n_{i_{0}}-1}\right)\right] \\
& <s\left[\frac{1}{2 s} d\left(x_{m_{i_{0}}}, f x_{m_{i_{0}}}\right)+\frac{1}{2 s} d\left(x_{m_{i_{0}}+1}, f x_{m_{i_{0}}+1}\right)\right] \\
& =\frac{1}{2}\left[d\left(x_{m_{i_{0}}}, x_{m_{i_{0}}+1}\right)+d\left(x_{m_{i_{0}}+1}, x_{m_{i_{0}}+2}\right)\right] \\
& \leq \frac{1}{2}\left[d\left(x_{m_{i_{0}}}, x_{m_{i_{0}}+1}\right)+d\left(x_{m_{i_{0}}}, x_{m_{i_{0}}+1}\right)\right]=d\left(x_{m_{i_{0}}}, x_{m_{i_{0}}+1}\right),
\end{aligned}
$$

which is a contradiction. Hence, either

$$
\frac{1}{2 s} d\left(x_{m_{i}}, f x_{m_{i}}\right) \leq d\left(x_{m_{i}}, x_{n_{i}-1}\right)
$$

or

$$
\frac{1}{2 s} d\left(x_{m_{i}+1}, f x_{m_{i}+1}\right) \leq d\left(x_{m_{i}+1}, x_{n_{i}-1}\right)
$$

holds for all $i \in \mathbb{N}$.

First suppose that

$$
\frac{1}{2 s} d\left(x_{m_{i}}, f x_{m_{i}}\right) \leq d\left(x_{m_{i}}, x_{n_{i}-1}\right)
$$

holds for all $i \in J$, where $J$ is an infinite set. As from Lemma 1.5, $\alpha\left(x_{m_{i}}, x_{n_{i}-1}\right) \geq 1$, according to $\left(\theta_{1}\right)$ we obtain that

$$
\begin{aligned}
\theta\left(s^{2} \cdot \frac{\varepsilon}{s}\right) & \leq \theta\left(s^{2} \cdot \limsup _{i \rightarrow \infty, i \in J} d\left(x_{m_{i}+1}, x_{n_{i}}\right)\right) \\
& \leq\left[\theta\left(\limsup _{i \rightarrow \infty, i \in J} M\left(x_{m_{i}}, x_{n_{i}-1}\right)\right)\right]^{k} \leq[\theta(\varepsilon)]^{k}
\end{aligned}
$$


because, from the definition of $M(x, y)$ and the above limits, we have

$$
\begin{aligned}
\limsup _{i \rightarrow \infty, i \in J} M\left(x_{m_{i}}, x_{n_{i}-1}\right) & \\
= & \limsup _{i \rightarrow \infty, i \in J} \max \left\{d\left(x_{m_{i}}, x_{n_{i}-1}\right), \frac{d\left(x_{m_{i}}, f x_{m_{i}}\right) d\left(x_{m_{i}}, f x_{n_{i}-1}\right)+d\left(x_{n_{i}-1}, f x_{n_{i}-1}\right) d\left(x_{n_{i}-1}, f x_{m_{i}}\right)}{1+s\left[d\left(x_{m_{i}}, x_{n_{i}-1}\right)+d\left(f x_{m_{i}}, f x_{n_{i}-1}\right)\right]},\right. \\
& \left.\frac{d\left(x_{m_{i}}, f x_{m_{i}}\right) d\left(x_{m_{i}}, f x_{n_{i}-1}\right)+d\left(x_{n_{i}-1}, f x_{n_{i}-1}\right) d\left(x_{n_{i}-1}, f x_{m_{i}}\right)}{1+d\left(x_{m_{i}}, f x_{n_{i}-1}\right)+d\left(x_{n_{i}-1}, f x_{m_{i}}\right)}\right\} \\
= & \limsup _{i \rightarrow \infty, i \in J} \max \left\{d\left(x_{m_{i}}, x_{n_{i}-1}\right), \frac{d\left(x_{m_{i}}, x_{m_{i}+1}\right) d\left(x_{m_{i}}, x_{n_{i}}\right)+d\left(x_{n_{i}-1}, x_{n_{i}}\right) d\left(x_{n_{i}-1}, x_{m_{i}+1}\right)}{1+s\left[d\left(x_{m_{i}}, x_{n_{i}-1}\right)+d\left(x_{m_{i}+1}, x_{n_{i}}\right)\right]},\right. \\
& \left.\frac{d\left(x_{m_{i}}, x_{m_{i}+1}\right) d\left(x_{m_{i}}, x_{n_{i}}\right)+d\left(x_{n_{i}-1}, x_{n_{i}}\right) d\left(x_{n_{i}-1}, x_{m_{i}+1}\right)}{1+d\left(x_{m_{i}}, x_{n_{i}}\right)+d\left(x_{n_{i}-1}, x_{m_{i}+1}\right)}\right\} \\
\leq & \varepsilon
\end{aligned}
$$

which implies that $\theta\left(s^{2} \cdot \frac{\varepsilon}{s}\right) \leq[\theta(\varepsilon)]^{k}$, a contradiction.

Now, if $J$ is a finite set, then we can assume that

$$
\frac{1}{2 s} d\left(x_{m_{i}+1}, f x_{m_{i}+1}\right) \leq d\left(x_{m_{i}+1}, x_{n_{i}-1}\right)
$$

holds for all $i \in \mathbb{N}$. Further, from (3.3) and using $\left(\mathrm{b}_{3}\right)$, we get

$$
\varepsilon \leq d\left(x_{m_{i}}, x_{n_{i}}\right) \leq s d\left(x_{m_{i}}, x_{m_{i}+2}\right)+s d\left(x_{m_{i}+2}, x_{n_{i}}\right) .
$$

Taking the upper limit as $i \rightarrow \infty$, we get

$$
\frac{\varepsilon}{s} \leq \limsup _{i \rightarrow \infty} d\left(x_{m_{i}+2}, x_{n_{i}}\right) .
$$

Also, from (3.4) and using $\left(b_{3}\right)$, we get

$$
d\left(x_{m_{i}+1}, x_{n_{i}-1}\right) \leq s d\left(x_{m_{i}+1}, x_{n_{i}}\right)+s d\left(x_{n_{i}}, x_{n_{i}-1}\right) .
$$

Taking the upper limit as $i \rightarrow \infty$, we get

$$
\limsup _{i \rightarrow \infty} d\left(x_{m_{i}+1}, x_{n_{i}-1}\right) \leq s \varepsilon
$$

From Lemma 1.5, $\alpha\left(x_{m_{i}+1}, x_{n_{i}-1}\right) \geq 1$, and so we have

$$
\begin{aligned}
\theta\left(s^{2} \cdot \frac{\varepsilon}{s}\right) & \leq \theta\left(s^{2} \cdot \limsup _{i \rightarrow \infty} d\left(x_{m_{i}+2}, x_{n_{i}}\right)\right) \\
& \leq\left[\theta\left(\limsup _{i \rightarrow \infty} M\left(x_{m_{i}+1}, x_{n_{i}-1}\right)\right)\right]^{k} \leq[\theta(s \varepsilon)]^{k}
\end{aligned}
$$

because

$$
\begin{aligned}
& \limsup _{i \rightarrow \infty} M\left(x_{m_{i}+1}, x_{n_{i}-1}\right) \\
& \quad=\limsup _{i \rightarrow \infty} \max \left\{d\left(x_{m_{i}+1}, x_{n_{i}-1}\right),\right.
\end{aligned}
$$




$$
\begin{aligned}
& \frac{d\left(x_{m_{i}+1}, f x_{m_{i}+1}\right) d\left(x_{m_{i}+1}, f x_{n_{i}-1}\right)+d\left(x_{n_{i}-1}, f x_{n_{i}-1}\right) d\left(x_{n_{i}-1}, f x_{m_{i}+1}\right)}{1+s\left[d\left(x_{m_{i}+1}, x_{n_{i}-1}\right)+d\left(f x_{m_{i}+1}, f x_{n_{i}-1}\right)\right]}, \\
& \left.\frac{d\left(x_{m_{i}+1}, f x_{m_{i}+1}\right) d\left(x_{m_{i}+1}, f x_{n_{i}-1}\right)+d\left(x_{n_{i}-1}, f x_{n_{i}-1}\right) d\left(x_{n_{i}-1}, f x_{m_{i}+1}\right)}{1+d\left(x_{m_{i}+1}, f x_{n_{i}-1}\right)+d\left(x_{n_{i}-1}, f x_{m_{i}+1}\right)}\right\} \\
= & \limsup _{i \rightarrow \infty} \max \left\{d\left(x_{m_{i}+1}, x_{n_{i}-1}\right),\right. \\
& \frac{d\left(x_{m_{i}+1}, x_{m_{i}+2}\right) d\left(x_{m_{i}+1}, x_{n_{i}}\right)+d\left(x_{n_{i}-1}, x_{n_{i}}\right) d\left(x_{n_{i}-1}, x_{m_{i}+2}\right)}{1+s\left[d\left(x_{m_{i}+1}, x_{n_{i}-1}\right)+d\left(x_{m_{i}+2}, x_{n_{i}}\right)\right]}, \\
& \left.\frac{d\left(x_{m_{i}+1}, x_{m_{i}+2}\right) d\left(x_{m_{i}+1}, x_{n_{i}}\right)+d\left(x_{n_{i}-1}, x_{n_{i}}\right) d\left(x_{n_{i}-1}, x_{m_{i}+2}\right)}{1+d\left(x_{m_{i}+1}, x_{n_{i}}\right)+d\left(x_{n_{i}-1}, x_{m_{i}+2}\right)}\right\} \\
\leq & s \varepsilon
\end{aligned}
$$

a contradiction. Therefore, in all cases $\left\{x_{n}\right\}$ is a $b$-Cauchy sequence, and hence $b$-completeness of $X$ yields that $\left\{x_{n}\right\} b$-converges to a point $x^{*} \in X$.

Remember that from (3.2) we get

$$
d\left(x_{n}, x_{n+1}\right) \leq d\left(x_{n-1}, x_{n}\right)
$$

for all $n \in \mathbb{N}$. Suppose that there exists $n_{0} \in \mathbb{N}$ such that

$$
\frac{1}{2 s} d\left(x_{n_{0}}, f x_{n_{0}}\right)>d\left(x_{n_{0}}, x^{*}\right)
$$

and

$$
\frac{1}{2 s} d\left(x_{n_{0}+1}, f x_{n_{0}+1}\right)>d\left(x_{n_{0}+1}, x^{*}\right) .
$$

Then from (3.7) we have

$$
\begin{aligned}
d\left(x_{n_{0}}, x_{n_{0}+1}\right) & \leq s\left[d\left(x_{n_{0}}, x^{*}\right)+d\left(x_{n_{0}+1}, x^{*}\right)\right] \\
& <s\left[\frac{1}{2 s} d\left(x_{n_{0}}, f x_{n_{0}}\right)+\frac{1}{2 s} d\left(x_{n_{0}+1}, f x_{n_{0}+1}\right)\right] \\
& =\frac{1}{2}\left[d\left(x_{n_{0}}, x_{n_{0}+1}\right)+d\left(x_{n_{0}+1}, x_{n_{0}+2}\right)\right] \\
& \leq \frac{1}{2}\left[d\left(x_{n_{0}}, x_{n_{0}+1}\right)+d\left(x_{n_{0}}, x_{n_{0}+1}\right)\right]=d\left(x_{n_{0}}, x_{n_{0}+1}\right),
\end{aligned}
$$

which is a contradiction. Hence, either

$$
\frac{1}{2 s} d\left(x_{n}, f x_{n}\right) \leq d\left(x_{n}, x^{*}\right)
$$

or

$$
\frac{1}{2 s} d\left(x_{n+1}, f x_{n+1}\right) \leq d\left(x_{n+1}, x^{*}\right)
$$

holds for all $n \in \mathbb{N}$. First, suppose that

$$
\frac{1}{2 s} d\left(x_{n}, f x_{n}\right) \leq d\left(x_{n}, x^{*}\right)
$$


holds for infinitely many values of $n$, say $n \in J$. Then, from (3.1), we have

$$
\theta\left(d\left(f x^{*}, f x_{n}\right)\right) \leq\left[\theta\left(M\left(x^{*}, x_{n}\right)\right)\right]^{k}
$$

for all $n \in J$ because

$$
\begin{aligned}
M\left(x^{*}, x_{n}\right)= & \max \left\{d\left(x^{*}, x_{n}\right), \frac{d\left(x^{*}, f x^{*}\right) d\left(x^{*}, f x_{n}\right)+d\left(x_{n}, f x_{n}\right) d\left(x_{n}, f x^{*}\right)}{1+s\left[d\left(x^{*}, x_{n}\right)+d\left(f x^{*}, f x_{n}\right)\right]},\right. \\
& \left.\frac{d\left(x^{*}, f x^{*}\right) d\left(x^{*}, f x_{n}\right)+d\left(x_{n}, f x_{n}\right) d\left(x_{n}, f x^{*}\right)}{1+d\left(x^{*}, f x_{n}\right)+d\left(x_{n}, f x^{*}\right)}\right\}
\end{aligned}
$$

for all $n \in \mathbb{N}$. Taking the limit as $n \rightarrow \infty$, with $n \in J$, in the above inequality we get that

$$
\lim _{n \rightarrow \infty, n \in J} \theta\left(d\left(f x^{*}, f x_{n}\right)\right)=1
$$

This implies that $\lim _{n \rightarrow \infty, n \in J} d\left(f x^{*}, f x_{n}\right)=0$. Applying Lemma 3.4, we deduce that

$$
f x^{*}=x^{*} .
$$

By a similar method we can obtain $f x^{*}=x^{*}$ when

$$
\frac{1}{2} d\left(x_{n+1}, f x_{n+1}\right) \leq d\left(x_{n+1}, x^{*}\right)
$$

holds for infinitely many values of $n$. Hence, we proved that $x^{*}$ is a fixed point of $f$.

Analogously, we can prove the following theorems.

Theorem 3.7 Let $(X, d)$ be a b-complete b-metric space with $s>1$, and let $f$ be a triangular $\alpha$-admissible mapping. Suppose that there exist $\theta \in \Theta$ and $k \in(0,1)$ such that

$$
\frac{1}{2 s} d(x, f x) \leq d(x, y) \quad \Longrightarrow \quad \alpha(x, y) \theta\left(s^{2} d(f x, f y)\right) \leq[\theta(M(x, y))]^{k}
$$

for all $x, y \in X$ with $f x \neq f y$, where

$$
M(x, y)=\max \left\{d(x, y), \frac{d(x, f x) d(y, f y)}{1+d(x, y)}, \frac{d(x, f x) d(y, f y)}{1+d(f x, f y)}\right\} .
$$

Also, suppose that the following assertions hold:

(i) there exists $x_{0} \in X$ such that $\alpha\left(x_{0}, f x_{0}\right) \geq 1$;

(ii) for any sequence $\left\{x_{n}\right\}$ in $X$ with $\alpha\left(x_{n}, x_{n+1}\right) \geq 1$, for all $n \in \mathbb{N} \cup\{0\}$, such that $x_{n} \rightarrow x$ as $n \rightarrow \infty$, we have $\alpha\left(x_{n}, x\right) \geq 1$ for all $n \in \mathbb{N} \cup\{0\}$.

Then $f$ has a fixed point.

Theorem 3.8 Let $(X, d)$ be a b-complete $b$-metric space with $s>1$, and let $f$ be a triangular $\alpha$-admissible mapping. Suppose that there exist $\theta \in \Theta$ and $k \in(0,1)$ such that

$$
\frac{1}{2 s} d(x, f x) \leq d(x, y) \quad \Longrightarrow \quad \alpha(x, y) \theta\left(s^{2} d(f x, f y)\right) \leq[\theta(M(x, y))]^{k}
$$


for all $x, y \in X$ with $f x \neq f y$, where

$$
\begin{aligned}
M(x, y)= & \max \left\{d(x, y), \frac{d(x, f x) d(y, f y)}{1+s[d(x, y)+d(x, f y)+d(y, f x)]},\right. \\
& \left.\frac{d(x, f y) d(x, y)}{1+s d(x, f x)+s^{3}[d(y, f x)+d(y, f y)]}\right\} .
\end{aligned}
$$

Also, suppose that the following assertions hold:

(i) there exists $x_{0} \in X$ such that $\alpha\left(x_{0}, f x_{0}\right) \geq 1$;

(ii) for any sequence $\left\{x_{n}\right\}$ in $X$ with $\alpha\left(x_{n}, x_{n+1}\right) \geq 1$, for all $n \in \mathbb{N} \cup\{0\}$, such that $x_{n} \rightarrow x$ as $n \rightarrow \infty$, we have $\alpha\left(x_{n}, x\right) \geq 1$ for all $n \in \mathbb{N} \cup\{0\}$.

Then $f$ has a fixed point.

The following corollaries are immediate consequences of the obtained theorems.

Corollary 3.9 Let $(X, d)$ be a b-complete b-metric space with $s>1$, and let $f$ be a triangular $\alpha$-admissible mapping. Suppose that there exist $\theta \in \Theta, k \in(0,1)$ and $\alpha, \beta, \gamma \in[0,1)$ with $\alpha+\beta+\gamma<1$ such that

$$
\begin{aligned}
& \frac{1}{2 s} d(x, f x) \leq d(x, y) \\
& \quad \Longrightarrow \quad \alpha(x, y) \theta\left(s^{2} d(f x, f y)\right) \leq\left[\theta\left(\alpha d(x, y)+\beta \frac{d(x, f x) d(y, f y)}{1+d(x, y)}+\gamma \frac{d(x, f x) d(y, f y)}{1+d(f x, f y)}\right)\right]^{k}
\end{aligned}
$$

for all $x, y \in X$ with $f x \neq f y$. Also, suppose that the following assertions hold:

(i) there exists $x_{0} \in X$ such that $\alpha\left(x_{0}, f x_{0}\right) \geq 1$;

(ii) for any sequence $\left\{x_{n}\right\}$ in $X$ with $\alpha\left(x_{n}, x_{n+1}\right) \geq 1$, for all $n \in \mathbb{N} \cup\{0\}$, such that $x_{n} \rightarrow x$ as $n \rightarrow \infty$, we have $\alpha\left(x_{n}, x\right) \geq 1$ for all $n \in \mathbb{N} \cup\{0\}$.

Then $f$ has a fixed point.

Corollary 3.10 Let $(X, d)$ be a b-complete b-metric space with $s>1$, and let $f$ be a triangular $\alpha$-admissible mapping. Suppose that there exist $\theta \in \Theta, k \in(0,1)$ and $\alpha, \beta, \gamma \in[0,1)$ with $\alpha+\beta+\gamma<1$ such that

$$
\begin{aligned}
\frac{1}{2 s} d(x, f x) \leq d(x, y) & \\
\Longrightarrow \quad \alpha(x, y) \theta\left(s^{2} d(f x, f y)\right) \leq & {\left[\theta \left(\alpha d(x, y)+\beta \frac{d(x, f x) d(x, f y)+d(y, f y) d(y, f x)}{1+s[d(x, f x)+d(y, f y)]}\right.\right.} \\
& \left.\left.+\gamma \frac{d(x, f x) d(x, f y)+d(y, f y) d(y, f x)}{1+d(x, f y)+d(y, f x)}\right)\right]^{k}
\end{aligned}
$$

for all $x, y \in X$ with $f x \neq f y$. Also, suppose that the following assertions hold:

(i) there exists $x_{0} \in X$ such that $\alpha\left(x_{0}, f x_{0}\right) \geq 1$;

(ii) for any sequence $\left\{x_{n}\right\}$ in $X$ with $\alpha\left(x_{n}, x_{n+1}\right) \geq 1$, for all $n \in \mathbb{N} \cup\{0\}$, such that $x_{n} \rightarrow x$ as $n \rightarrow \infty$, we have $\alpha\left(x_{n}, x\right) \geq 1$ for all $n \in \mathbb{N} \cup\{0\}$.

Then $f$ has a fixed point.

Corollary 3.11 Let $(X, d)$ be a b-complete b-metric space with $s>1$, and let $f$ be a triangular $\alpha$-admissible mapping. Suppose that there exist $\theta \in \Theta, k \in(0,1)$ and $\alpha, \beta, \gamma \in[0,1)$ 
with $\alpha+\beta+\gamma<1$ such that

$$
\begin{aligned}
\frac{1}{2 s} d(x, f x) \leq d(x, y) & \\
\Longrightarrow \quad \alpha(x, y) \theta\left(s^{2} d(f x, f y)\right) \leq & {\left[\theta \left(\alpha d(x, y)+\beta \frac{d(x, f x) d(y, f y)}{1+s[d(x, y)+d(x, f y)+d(y, f x)]}\right.\right.} \\
& \left.\left.+\gamma \frac{d(x, f y) d(x, y)}{1+s d(x, f x)+s^{3}[d(y, f x)+d(y, f y)]}\right)\right]^{k}
\end{aligned}
$$

for all $x, y \in X$ with $f x \neq f y$. Also, suppose that the following assertions hold:

(i) there exists $x_{0} \in X$ such that $\alpha\left(x_{0}, f x_{0}\right) \geq 1$;

(ii) for any sequence $\left\{x_{n}\right\}$ in $X$ with $\alpha\left(x_{n}, x_{n+1}\right) \geq 1$, for all $n \in \mathbb{N} \cup\{0\}$, such that $x_{n} \rightarrow x$ as $n \rightarrow \infty$, we have $\alpha\left(x_{n}, x\right) \geq 1$ for all $n \in \mathbb{N} \cup\{0\}$.

Then $f$ has a fixed point.

Taking $\theta(t)=e^{t}$ for all $t>0$, in the above corollaries we obtain the following new results.

Corollary 3.12 Let $(X, d)$ be a b-complete b-metric space (with parameter $s>1$ ), and let $f$ be a triangular $\alpha$-admissible mapping. Suppose that there exist $\theta \in \Theta, k \in(0,1)$ and $\alpha, \beta, \gamma \in[0,1)$ with $\alpha+\beta+\gamma<1$ such that

$$
\begin{aligned}
& \frac{1}{2 s} d(x, f x) \leq d(x, y) \\
& \quad \Longrightarrow \quad \ln \alpha(x, y)+s^{2} d(f x, f y) \leq k\left[\alpha d(x, y)+\beta \frac{d(x, f x) d(y, f y)}{1+d(x, y)}+\gamma \frac{d(x, f x) d(y, f y)}{1+d(f x, f y)}\right]
\end{aligned}
$$

for all $x, y \in X$ with $f x \neq f y$. Also, suppose that the following assertions hold:

(i) there exists $x_{0} \in X$ such that $\alpha\left(x_{0}, f x_{0}\right) \geq 1$;

(ii) for any sequence $\left\{x_{n}\right\}$ in $X$ with $\alpha\left(x_{n}, x_{n+1}\right) \geq 1$, for all $n \in \mathbb{N} \cup\{0\}$, such that $x_{n} \rightarrow x$ as $n \rightarrow \infty$, we have $\alpha\left(x_{n}, x\right) \geq 1$ for all $n \in \mathbb{N} \cup\{0\}$.

Then $f$ has a fixed point.

Corollary 3.13 Let $(X, d)$ be a b-complete b-metric space (with parameter $s>1$ ), and let $f$ be a triangular $\alpha$-admissible mapping. Suppose that there exist $\theta \in \Theta, k \in(0,1)$ and $\alpha, \beta, \gamma \in[0,1)$ with $\alpha+\beta+\gamma<1$ such that

$$
\begin{aligned}
\frac{1}{2 s} d(x, f x) \leq d(x, y) & \\
\Longrightarrow \ln \alpha(x, y)+s^{2} d(f x, f y) \leq & k\left[\alpha d(x, y)+\beta \frac{d(x, f x) d(x, f y)+d(y, f y) d(y, f x)}{1+s[d(x, f x)+d(y, f y)]}\right. \\
& \left.+\gamma \frac{d(x, f x) d(x, f y)+d(y, f y) d(y, f x)}{1+d(x, f y)+d(y, f x)}\right]
\end{aligned}
$$

for all $x, y \in X$ with $f x \neq f y$. Also, suppose that the following assertions hold:

(i) there exists $x_{0} \in X$ such that $\alpha\left(x_{0}, f x_{0}\right) \geq 1$;

(ii) for any sequence $\left\{x_{n}\right\}$ in $X$ with $\alpha\left(x_{n}, x_{n+1}\right) \geq 1$, for all $n \in \mathbb{N} \cup\{0\}$, such that $x_{n} \rightarrow x$ as $n \rightarrow \infty$, we have $\alpha\left(x_{n}, x\right) \geq 1$ for all $n \in \mathbb{N} \cup\{0\}$.

Then $f$ has a fixed point. 
Corollary 3.14 Let $(X, d)$ be a b-complete b-metric space (with parameter $s>1$ ), and let $f$ be a triangular $\alpha$-admissible mapping. Suppose that there exist $\theta \in \Theta, k \in(0,1)$ and $\alpha, \beta, \gamma \in[0,1)$ with $\alpha+\beta+\gamma<1$ such that

$$
\begin{aligned}
\frac{1}{2 s} d(x, f x) \leq d(x, y) & \\
\Longrightarrow \quad \ln \alpha(x, y)+s^{2} d(f x, f y) \leq & k\left[\alpha d(x, y)+\beta \frac{d(x, f x) d(y, f y)}{1+s[d(x, y)+d(x, f y)+d(y, f x)]}\right. \\
& \left.+\gamma \frac{d(x, f y) d(x, y)}{1+s d(x, f x)+s^{3}[d(y, f x)+d(y, f y)]}\right]
\end{aligned}
$$

for all $x, y \in X$ with $f x \neq f y$. Also, suppose that the following assertions hold:

(i) there exists $x_{0} \in X$ such that $\alpha\left(x_{0}, f x_{0}\right) \geq 1$;

(ii) for any sequence $\left\{x_{n}\right\}$ in $X$ with $\alpha\left(x_{n}, x_{n+1}\right) \geq 1$, for all $n \in \mathbb{N} \cup\{0\}$, such that $x_{n} \rightarrow x$ as $n \rightarrow \infty$, we have $\alpha\left(x_{n}, x\right) \geq 1$ for all $n \in \mathbb{N} \cup\{0\}$.

Then $f$ has a fixed point.

The following example supports our results.

Example 3.15 Let $X=\mathbb{R}$. Define a metric $d$ on $X$ by $d(x, y)=(x-y)^{2}$. Clearly, $(X, d)$ is a complete $b$-metric space, with $s=2$. Also, let $k=\frac{1}{2}$ and define $f: X \rightarrow X, \theta:(0, \infty) \rightarrow$ $(1, \infty)$ and $\alpha: X \times X \rightarrow[0, \infty)$ by

$$
\begin{aligned}
& f(x)=\left\{\begin{array}{ll}
\frac{1}{4} x & \text { if } x \in\{0,4,5\}, \\
2 x, & \text { otherwise }
\end{array} \quad \theta(t)=\cosh t\right. \\
& \alpha(x, y)= \begin{cases}1 & \text { if } x, y \in\{0,4,5\}, \\
0, & \text { otherwise }\end{cases}
\end{aligned}
$$

First, we assume that $\frac{1}{4} d(x, f x) \leq d(x, y)$ and $\alpha(x, y) \geq 1$ with $f x \neq f y$. Then,

$$
(x, y) \in\{(0,4),(0,5),(4,0),(4,5),(5,0),(5,4)\} .
$$

Now, we consider the following cases:

- Let $(x, y)=(0,4)$, then

$$
\begin{aligned}
\alpha(x, y) \theta\left(s^{2} d(f x, f y)\right) & =\cosh (4 \cdot d(0,1))=27.3082328 \\
& \leq \sqrt{\cosh (16)}=\sqrt{4443055.26} \\
& =2107.85561 \leq[\theta(M(0,4))]^{k}
\end{aligned}
$$

- Let $(x, y)=(0,5)$, then

$$
\begin{aligned}
\alpha(x, y) \theta\left(s^{2} d(f x, f y)\right) & =\cosh \left(4 \cdot d\left(0, \frac{5}{4}\right)\right)=259.007378 \\
& \leq \sqrt{\cosh (25)}=\sqrt{3.60024497 \times 10^{10}} \\
& =189743.115 \leq[\theta(M(0,5))]^{k} .
\end{aligned}
$$


- Let $(x, y)=(4,5)$, then

$$
\begin{aligned}
\alpha(x, y) \theta\left(s^{2} d(f x, f y)\right) & =\cosh \left(4 \cdot d\left(1, \frac{5}{4}\right)\right)=1.0314131 \\
& \leq \sqrt{\cosh (1)}=\sqrt{1.54308063} \\
& =1.24220797 \leq[\theta(M(4,5))]^{k} .
\end{aligned}
$$

We deduce that

$$
\frac{1}{2 s} d(x, f x) \leq d(x, y) \quad \Longrightarrow \quad \alpha(x, y) \theta\left(s^{2} d(f x, f y)\right) \leq[\theta(M(x, y))]^{k}
$$

for all $x, y \in X$ with $f x \neq f y$, where (we recall)

$$
M(x, y)=\max \left\{d(x, y), \frac{d(x, f x) d(y, f y)}{1+d(x, y)}, \frac{d(x, f x) d(y, f y)}{1+d(f x, f y)}\right\} .
$$

Therefore, all conditions of Theorem 3.7 hold true and $f$ has a fixed point. Here, $x=0$ is a fixed point of $f$.

\section{Competing interests}

The authors declare that they have no competing interests.

\section{Authors' contributions}

All authors contributed equally to the writing of this paper. All authors read and approved the final manuscript.

\section{Author details}

'Department of Mathematics, King Abdulaziz University, P.O. Box 80203, Jeddah, 21589, Saudi Arabia. ${ }^{2}$ Department of Mathematics, Gilan-E-Gharb Branch, Islamic Azad University, Gilan-E-Gharb, Iran. ${ }^{3}$ Department of Mathematics, College of Science, King Saud University, P.O. Box 2455, Riyadh, 11451, Saudi Arabia. ${ }^{4}$ Department of Mathematics and Computer Sciences, Università degli Studi di Palermo, Via Archirafi 34, Palermo, 90123, Italy.

\section{Acknowledgements}

The third author extends his sincere appreciation to the Deanship of Scientific Research at King Saud University for funding this Prolific Research Group (PRG-1436-10).

Received: 20 March 2015 Accepted: 30 September 2015 Published online: 09 October 2015

\section{References}

1. Banach, S: Sur les operations dans les ensembles abstraits et leur application aux equations integrales. Fundam. Math. 3, 133-181 (1922) (in French)

2. Boyd, DW, Wong, JSW: On nonlinear contractions. Proc. Am. Math. Soc. 20, 458-464 (1969)

3. Ćirić, L: Generalized contractions and fixed-point theorems. Publ. Inst. Math. (Belgr.) 12(26), 19-26 (1971)

4. Ćirić, L: A generalization of Banach's contraction principle. Proc. Am. Math. Soc. 45(2), 267-273 (1974)

5. Meir, A, Keeler, E: A theorem on contraction mappings. J. Math. Anal. Appl. 28, 326-329 (1969)

6. Ćirić, L: Multi-valued nonlinear contraction mappings. Nonlinear Anal. 71, 2716-2723 (2009)

7. Mizoguchi, N, Takahashi, W: Fixed point theorems for multivalued mappings on complete metric spaces. J. Math. Anal. Appl. 141, 177-188 (1989)

8. Geraghty, M: On contractive mappings. Proc. Am. Math. Soc. 40, 604-608 (1973)

9. Reich, S: Some remarks concerning contraction mappings. Can. Math. Bull. 14, 121-124 (1971)

10. Wardowski, D: Fixed points of a new type of contractive mappings in complete metric spaces. Fixed Point Theory Appl. 2012, $94(2012)$

11. Nashine, HK, Imdad, M, Hasan, M: Common fixed point theorems under rational contractions in complex valued metric spaces. J. Nonlinear Sci. Appl. 7, 42-50 (2014)

12. Jaggi, DS: Some unique fixed point theorems. Indian J. Pure Appl. Math. 8(2), 223-230 (1977)

13. Ozturk, M, Basarir, M: On some common fixed point theorems with rational expressions on cone metric spaces over a Banach algebra. Hacet. J. Math. Stat. 41(2), 211-222 (2012)

14. Kannan, R: Some results on fixed points. Bull. Calcutta Math. Soc. 60, 71-76 (1968)

15. Chatterjea, SK: Fixed point theorems. C. R. Acad. Bulgare Sci. 25, 727-730 (1972)

16. Samet, B, Vetro, C, Vetro, P: Fixed point theorem for $\alpha$ - $\psi$-contractive type mappings. Nonlinear Anal. 75, $2154-2165$ (2012)

17. Karapınar, E, Kumam, P, Salimi, P: On $\alpha$ - $\psi$-Meir-Keeler contractive mappings. Fixed Point Theory Appl. 2013, 94 (2013) 
18. Jleli, M, Samet, B: A new generalization of the Banach contraction principle. J. Inequal. Appl. 2014, 38 (2014)

19. Czerwik, S: Contraction mappings in b-metric spaces. Acta Math. Inform. Univ. Ostrav. 1, 5-11 (1993)

20. Roshan, JR, Parvaneh, V, Sedghi, S, Shobkolaei, N, Shatanawi, W: Common fixed points of almost generalized $(\psi, \varphi)_{s}$-contractive mappings in ordered $b$-metric spaces. Fixed Point Theory Appl. 2013, 159 (2013)

21. Boriceanu, M: Fixed point theory for multivalued generalized contractions on a set with two $b$-metrics. Stud. Univ. Babes-Bolyai, Math. 54(3), 3-14 (2009)

22. Hussain, N, Đorić, D, Kadelburg, Z, Radenović, S: Suzuki-type fixed point results in metric type spaces. Fixed Point Theory Appl. 2012, 126 (2012). doi:10.1186/1687-1812-2012-126

23. Edelstein, M: On fixed and periodic points under contractive mappings. J. Lond. Math. Soc. 37, 74-79 (1962)

24. Suzuki, T: A new type of fixed point theorem in metric spaces. Nonlinear Anal., Theory Methods Appl. 71(11), 5313-5317 (2009)

25. Shobkolaei, N, Sedghi, S, Roshan, JR, Hussain, N: Suzuki-type fixed point results in metric-like spaces. J. Funct. Spaces Appl. 2013, Article ID 143686 (2013)

26. Salimi, P, Karapınar, E: Suzuki-Edelstein type contractions via auxiliary functions. Math. Probl. Eng. 2013, Article ID $648528(2013)$

27. Suzuki, T: A generalized Banach contraction principle that characterizes metric completeness. Proc. Am. Math. Soc. $136,1861-1869(2008)$

28. Shahkoohi, RJ, Razani, A: Some fixed point theorems for rational Geraghty contractive mappings in ordered $b$-metric spaces. J. Inequal. Appl. 2014, 373 (2014)

\section{Submit your manuscript to a SpringerOpen ${ }^{\odot}$ journal and benefit from:}

- Convenient online submission

- Rigorous peer review

- Immediate publication on acceptance

Open access: articles freely available online

High visibility within the field

- Retaining the copyright to your article 